departments associated to heavier and less autonomous patient handling activity, were most affected by back MSD.

Discussion Our investigation identifies biomechanical risk factor of MSD among nurses and suggests the necessity of preventive actions according to exposure leve.

\section{NEWLY DEVELOPED AND REDESIGNED KEY INDICATOR METHODS FOR ASSESSMENT OF DIFFERENT PHYSICAL WORKLOADS - KEY ELEMENTS OF THE VALIDATION STUDY}

\footnotetext{
${ }^{1,2} \mathrm{~A}$ Klussmann*, ${ }^{3} \mathrm{~F}$ Liebers, ${ }^{3} \mathrm{~F}$ Brandstädt, ${ }^{3} \mathrm{M}$ Schust, ${ }^{1} \mathrm{P}$ Serafin, ${ }^{1} \mathrm{~A}$ Schäfer, ${ }^{1} \mathrm{H}$ Gebhardt, ${ }^{4} \mathrm{~B}$ Hartmann, ${ }^{3} \mathrm{U}$ Steinberg. 'Institute of Occupational Health, Safety and Ergonomics (ASER), Wuppertal, Germany; ' University of Wuppertal, Chair of Human Engineering, Wuppertal, Germany; ${ }^{3}$ Federal Institute for Occupational Safety and Health (BAuA), Berlin, Germany; ${ }^{4}$ ArbMedErgo Consultant, Hamburg, Germany
}

\subsection{6/oemed-2018-ICOHabstracts.719}

Introduction The assessment of work tasks with physical workloads is crucial to estimate the work-related health risks of employees. Three key indicator methods (KIMs) are available for risk assessment regarding manual lifting, holding and carrying of loads, manual pulling and pushing, and manual handling operations. Three further KIMs regarding whole-body forces, awkward body postures and body movement have been developed de novo. The development of a combined method for mixed exposures is planned. All methods will be validated regarding face validity, reliability, convergent validity, criterion validity.

Methods A mixed-methods study was designed for the validation of KIMs. The following working hypotheses (WH) are tested:

- WH 1: The KIMs reflect adequately the construct to be measured (face validity).

- WH 2: No relevant deviations occur between different users using KIMs and assessing the same workplaces (reliability).

- WH 3: Assessing workplaces using the KIMs and other screening methods will result in no relevant differences (convergent validity).

- WH 4: It is assumed that employees at workplaces with high KIM risk scores show adverse health related outcomes more frequently than non-exposed workers (criterion validity).

With this background a field study was conducted in companies of different sizes and branches in Germany as part of the joint project MEGAPHYS (multilevel risk assessment of physical workloads).

Ethics and dissemination: The study was planned and conducted in accordance with the Declaration of Helsinki, the design was approved by ethics committees. We intend to publish validated KIMs in 2018.

Acknowledgements/funding: The (further) development and validation of the KIMs is part of project MEGAPHYS funded by BAuA and the German Social Accident Insurance (DGUV). Further MEGAPHYS partners are Institute for Occupational Safety and Health of DGUV (IFA), Institute of Ergonomics at the Darmstadt University of Technology (IAD) and Leibniz Research Centre for Working Environment and Human Factors (IfADo).
1285 ASSOCIATION OF PSYCHOLOGICAL DISTRESS AND WORK-RELATED FACTORS AND MULTISITE MUSCULOSKELETAL PAIN AMONG TEACHERS IN MALAYSIA

${ }^{1,2}$ VC Hoe, ${ }^{1} \mathrm{FM}$ Moy, ${ }^{1} \mathrm{NN}$ Hairi, ${ }^{1} \mathrm{~S}$ Rampal, ${ }^{1} \mathrm{AM}$ Bulgiba. ${ }^{1}$ Centre for Occupational and Environmental Health-UM, Department of Social and Preventive Medicine, Faculty of Medicine, University of Malaya, Malaya, Malaya; ${ }^{2} J u l i u s$ Centre University of Malaya, Department of Social and Preventive Medicine, Faculty of Medicine, University of Malaya, Malaya, Malaysia

\subsection{6/oemed-2018-ICOHabstracts.720}

Introduction Work-related factors are known to be associated with musculoskeletal pain (MSP), however psychological distress may also play an important role. The study aims to evaluated the association between psychological distress and workrelated factors, and multisite MSP among teachers.

Methods This is a cross-sectional study conducted among teachers from six states in the Peninsular of Malaysia. Information on demographic characteristics, psychological distress, work-related factors and MSP from seven anatomical sites were collected using a self-administered questionnaire. Weight and height were measured using standardised methods. The association between MSP at three or more sites in the past month, and psychological distress and work-related factors were assessed using multivariate logistic regression.

Results 6796 teachers from 391 schools completed the questionnaire. The prevalence of self-reported MSP at three or more sites in past month were $38.22 \%$. The three most common sites were neck (42.15\%), shoulder (37.31\%) and feet (36.28\%). Psychological distress was more strongly associated with multisite MSP as compared to work-related factors, after controlling for potential confounders, i.e., age, gender, ethnicity, Body Mass Index, marital status and education level. Psychological distress symptoms like anxiety displayed the highest odds (Odds Ratio (OR) 2.27; 95\% Confidence Intervals (95\% CI) 1.97 to 2.63), followed with depression (OR 1.43; 95\% CI: 1.15 to 1.78 ) and stress (OR 1.35 ; 95\% CI: 1.03 to 1.76). The work-related factors with statistical significant findings were administrative duties $(<4 \mathrm{hr} /$ day) (OR 1.37; 95\% CI: 1.12 to 1.68 ), teaching ( $<15$ years) (OR 1.21; 95\% CI: 1.00 to 1.47$)$ and high psychological job demand (OR 1.05; 95\% CI: 1.04 to 1.07). Other work-related factors did not show any association.

Discussion The study found that psychological distress, i.e., anxiety, depression and stress have stronger association with multisite MSP. Intervention to reduce multisite MSP should include psychological distress along with the improving work processes.

\section{PREVALENCE OF MUSCULOSKELETAL DISEASES IN BANRO NAMOYA GOLD MINING WORKERS ATTENDING COMPANY CLINIC FROM JANUARY 2015 TO DECEMBER 2016}

${ }^{1}$ Onyimbo Kerama*, ${ }^{2}$ Kibor Kipkemoi Keitany. ${ }^{1}$ Chief Medical Officer, Banro Namoya Gold Mining, Democratic Republic of Congo; ${ }^{2}$ Occupational Health Practitioner, Department of Promotive and preventive health services, Ministry of Health, Kenya

10.1136/oemed-2018-ICOHabstracts.721 
Introduction Musculoskeletal disorders (MSD) are of great concern among miners in Democratic Republic of Congo. This study sought to determine the prevalence of musculoskeletal disorders and associated factors among Namoya Mining workers who attended the company clinic between January 2015 and December 2016.

Method The study utilised company clinic data to find out the prevalence of MSDs among mine workers who attended mine's primary care clinic. Diagnoses of musculoskeletal disorders for the two year period were noted. Among those who had MSDs, other recorded data was extracted which included age, type of work, type of MSD, and management offered.

Results There were a total of 9753 clinic visits for the 2 year period of which MSDs accounted for 15.5\%. In 2015, 877 (18.47\%) MSD diagnoses were made of a total of 4747 who visited the clinic and 685 (13.6\%) MSDs noted of 5006 clinic visits in 2016. Back pain was the most common contributing 82.2\% of all MSDs while Work-Related Upper Limb Disorders (WRULDs) accounted for $8 \%$. The most affected were aged $30-40,78 \%$ and majority were shovel handlers (56\%) and mining operators/drivers (42\%). Over the 2 year period 1600 lumbar belts were issued and 7 surgical interventions done (discectomy) and over 10,000 $100 \mathrm{mg}$ of diclofenac sodium tablets prescribed

Discussion The estimated prevalence of MSDs at $15.5 \%$ is high compared to data from USA which was $5 \%$ before technological advancements (1983-1984) and 4\% after technological advancement (2003-2004). This might be attributed to the intensity of work. The management of MSDs can increase expenditure on medical and orthopaedic supplies and therefore need for preventive measures. Due to limited information recorded a comprehensive study is recommended to establish other related factors.

\section{PREVALENCE AND RISK FACTORS CORRELATED WITH OCCUPATIONAL BACK PAIN AMONG WORKERS IN ELECTRONIC INDUSTRY}

\footnotetext{
${ }^{1} \mathrm{P}$ Suggaravetsiri*, ${ }^{2,3} \mathrm{~S}$ Chaiklieng*. 'Department of Epidemiology and Biostatistics, Faculty of Public Health, Khon Kaen University, Thailand; '2Department of Environmental Health, Occupational Health and Safety, Faculty of Public Health, Khon Kaen University, Khon Kaen, Thailand; ${ }^{3}$ Research Centre in Back, Neck, Other Joint Pain and Human Performance (BNOJPH), Khon Kaen University
}

\subsection{6/oemed-2018-ICOHabstracts.722}

Introduction Persistent back pain is common in society and is clearly an occupation-related problem. The symptoms are prevalent among industrial workers involved sedentary work with prolonged sitting and occasional standing. The nature of industrially electronic work is repetitive and sedentary work which might increase back pain risk. This cross-sectional study aimed to identify the risk factors correlated with back pain among electronic workers at northeast, Thailand.

Methods There were 354 workers selected by simple random sampling from the electronic process of industry. Data were collected by an interview with the structural questionnaires, observation for ergonomics risk assessment with the standard tools of RULA and occupational stress test. Risk factors were identified by multiple logistic regressions with adjusted odd ratio $\left(\mathrm{OR}_{\mathrm{adj}}\right)$ and $95 \%$ confidence interval at $\mathrm{p}$-value $<0.05$.
Results The result showed that most workers were operator (92.09\%), age was 20-29 years old (63.84\%). Almost workers had work experience less than 5 years $(75.71 \%)$ and repetitive work $(83.62 \%)$. The highest risk from RULA found in workers had alternative sitting and standing/walking posture over shift work (68.49\%) and also in the group of machine controlled and changing material (71.70\%). The prevalence of back pain was $20.62 \%$ (95\% CI: 16.38 to 24.86 ) which was the highest prevalence among other areas. Risk factors significantly correlated with occupational back pain were low decision making $\left(\mathrm{OR}_{\mathrm{adj}}=2.26\right.$; 95\% CI: 1.26 to 4.05$)$, no exercise $\left(\mathrm{OR}_{\mathrm{adj}}=8.30 ; 95 \% \mathrm{CI}: 1.35\right.$ to 24.28$)$, overtime work $\left(\mathrm{OR}_{\mathrm{adj}}=3.39\right.$; $95 \% \mathrm{CI}: 1.16$ to 9.88$)$, repetitive posture $\left(\mathrm{OR}_{\mathrm{adj}}=2.94 ; 95 \% \mathrm{CI}: 1.19\right.$ to 7.29$)$ and very high ergonomics risk assessed by RULA $\left(\mathrm{OR}_{\mathrm{adj}}=2.48 ; 95 \% \mathrm{CI}\right.$ : 1.20 to 6.60; p-value $=0.018)$.

Conclusion This study indicated that the high ergonomics risk at machine controlled station and alternative sitting and standing stations must be implemented change soon. Work rotation management is suggested to provide in the working process. Repetitive work, low decision, and long overtime work should be considered for safety management in order to prevent back pain among electronic workers.

\section{CERVICAL PAIN IN TOBACCO FARMERS IN SOUTHERN BRAZIL}

${ }^{1}$ Anaclaudia Gastal Fassa*, 'Maitê Peres de Carvalho, ${ }^{1}$ Neice Muller Xavier Faria, ${ }^{2}$ Rodrigo Dalke Meucci, ${ }^{1}$ Nadia Spada Fiori. ${ }^{1}$ Federal University of Pelotas, Pelotas, Rio Grande do Sul, Brazil, ${ }^{2}$ Foundation Federal University of Rio Grande, Rio Grande, Rio Grande do Sul, Brazil

\subsection{6/oemed-2018-ICOHabstracts.723}

Introduction More than 200000 families are included in tobacco farming in Brazil. In harvesting, baling, cutting wood among other activities the farmers are exposed to vicious position, physical effort, repetitive movements and vibrations. Thus, this study evaluated the prevalence and factors associated with cervical pain in tobacco farmers in southern Brazil.

Methods A cross-sectional study was carried out with a representative sample of 2469 tobacco farmers from the municipality of São Lourenço do Sul/RS/Brazil. Cervical pain was characterised by an adaptation of the Nordic Questionnaire for Musculoskeletal Symptoms. The multivariate analysis was performed by Poisson regression, following a hierarchical model.

Results The prevalence of cervical pain in the last year was $7.4 \%, 9.1 \%$ for women and 6.2\% for men. Work at intense or accelerated pace and green tobacco sickness in the last year were positively associated with cervical pain in both sexes. However, smoking and baling were risk factors among women, while older age, using heavy chainsaw and having suffered pesticide poisoning showed a risk among men.

Conclusion The prevalence of cervical pain is similar to that found in other studies in farmers, but risk activities are marked by the sexual division of labour and are related to ergonomic exposures. The study points to the need to deepen understanding about the role of nicotine exposure in musculoskeletal problems. The mechanisation of the harvest and the activities needed to heal the leaf could reduce cervical pain among smokers. 